\title{
Contribution of a Reflective Debriefing to Nursing Students' Clinical Judgment in Patient Deterioration Simulations: A Mixed-Methods Study
}

Patrick Lavoie, RN, Ph.D., Post-doctoral fellow, William F. Connell School of Nursing, Boston College, Boston, USA.

Jacinthe Pepin, RN, Ph.D., Professor and Director of the Center for Innovation in Nursing Education (CIFI), Faculty of Nursing, Université de Montréal, Montréal, Canada.

Sylvie Cossette, RN, Ph.D., Vice-dean, research and international relations, Faculty of Nursing, Université de Montréal, Montréal, Canada. Researcher at the Montreal Heart Institute, Montréal, Canada.

This study was conducted for the first author's doctoral dissertation. The first author received doctoral scholarships from the Quebec Nursing Intervention Research Network (RRISIQ), funded by the Fonds de recherche du Québec - Santé, (FRQS) from the Fonds de recherche du Québec - Société et Culture (FRQSC), and from the Ministère de l'Éducation, de l'Enseignement supérieur et de la Recherche du Québec. The Équipe FUTUR, funded by the FRQSC, supported the editing of this paper.

Corresponding author: Patrick Lavoie, patrick.lavoie.1@umontreal.ca

Coauthors: jacinthe.pepin@umontreal.ca, sylvie.cossette.inf@umontreal.ca 


\begin{abstract}
$\underline{\text { ABSTRACT }}$
Background: While reflection is a hallmark of debriefing, there is little understanding of how it contributes to nursing students' clinical judgment.

Objectives: The aim of this study was to describe how nursing students perceived that the Reflective dEbriefing after a PatieNt Deterioration simulation (REsPoND) fostered learning and how it contributed to their clinical judgment in patient deterioration simulations.

Design: A sequential explanatory mixed-methods study.

Participants: Nineteen students who showed the greatest clinical judgment score variation in a randomized controlled trial of the effectiveness of REsPoND.

Methods: Students participated in interviews on their learning experience in REsPoND. Data were subjected to thematic analysis and themes were contrasted according to students' score variations.

Results: Through guided exchanges with their peers, students configured a causes-observationsinterventions framework that embodied their understanding of the patient's situation. They evaluated their own simulation performance based on that framework. The contribution of REsPoND to students' clinical judgment differed depending on (1) the value placed on the review of the simulation through a systematic assessment approach; (2) their focus on anticipating the situation or on performing in the simulation; and (3) their preference for who participated more in debriefing.

Conclusion: Clinical judgment might be improved when a systematic assessment approach is used to structure debriefing. The relationship between reflection and self-assessment during debriefing remains to be disentangled.
\end{abstract}




\section{INTRODUCTION}

Simulation with debriefing is meant to improve nursing students' clinical judgment when a patient is deteriorating (Fisher \& King, 2013; Liaw et al., 2011a). While debriefing may be the most important aspect of simulation-based teaching (Raemer et al., 2011), there is little knowledge of the mechanisms by which it contributes to students' learning and especially to their clinical judgment of patient deterioration. Debriefing is a retrospective analysis of an event (Cant \& Cooper, 2011) and a guided reflection for experiential learning (Fanning \& Gaba, 2007). Recent literature reviews (Cheng et al., 2014; Raemer et al., 2011) have indicated that, overall, there are relatively poor descriptions of debriefing characteristics and a scarcity of research on approaches to debriefing. Reflection is framed as a hallmark of debriefing, which sets it apart from the more one-sided evaluative feedback on students' performance; despite this, the two processes are often confused (Cheng et al., 2014). The effectiveness of more reflective debriefings remains relatively unexplored, despite the fact that previous studies have reported the positive outcomes from reflective debriefings (Dreifuerst, 2012; Forneris et al., 2015).

\section{BACKGROUND}

This paper reports on an evaluative study of a new debriefing approach, the "Reflective dEbriefing after a PatieNt Deterioration simulation" (REsPoND) (Lavoie et al., 2015). This debriefing approach is based on the premise that reflection on a simulated patient deterioration experience can improve nursing students' clinical judgment.

\section{Theories of Debriefing}

Educational debriefing is grounded in experiential learning theories (Lederman, 1992). As such, it is intrinsically associated with the concept of reflection (Fanning \& Gaba, 2007), and differs from feedback or assessment in that it requires a two-way communication process between educators and students to help students understand the situation and develop strategies to improve in the future (Cant \& Cooper, 2011). Models of debriefing include attention to learners' emotional reactions, description and analysis of the experience to make sense of it, and generalization to apply learning to real-life situations (Fanning \& Gaba, 2007).

Model of Clinical Judgment 
In Tanner's (2006) research-based model, clinical judgment is an interpretation or a conclusion about a patient's situation. To make such judgments, nurses must notice when their observations do not fit their expectations of a patient's situation. Such expectations are drawn from their theoretical knowledge, practical knowledge of patients with similar conditions, and their knowledge of the particular patient. Noticing triggers reasoning patterns to interpret the meaning of the data and come to an understanding of the situation in order to decide on a response. Through reflection, nurses could develop their capabilities for clinical judgment in the future.

\section{Theory of Reflection}

According to Dewey (1910/2007), reflection is a fivefold process: (1) occurrence of a problematic situation, (2) deliberate observation to define the problem, (3) inference of an explicative hypothesis, (4) elaboration of its implications, and (5) experimentation and subsequent formation of knowledge. Reflection enables individuals to understand the meaning of a problematic situation, which is the relationship between causes, actions, and consequences. Two outcomes follow reflection: improvement of observation skills and the development of predispositions to act in a certain manner regarding similar situations.

\section{REsPoND's Theory}

REsPoND's theory (Lavoie et al., 2015) posits that reflection on a simulated patient deterioration experience can improve nursing students' clinical judgment. Hence, the outcomes of reflection as described by Dewey (1910/2007) are interwoven with the elements of clinical judgment: improvement of observation skills relates to better noticing, understanding the meaning of a situation refers to sound interpretation of a patient's situation, and developing predispositions to act is akin to learning how to respond to the situation.

As such, the questions in REsPoND enact the five steps of reflection. REsPoND begins by asking students how they felt during the simulation, a problematic situation (1) supposed to trigger reflection, before progressing on to more reflective questions. Deliberate observation (2) occurs through a recap of students' observations through the primary and secondary assessment survey ${ }^{1}$

\footnotetext{
${ }^{1}$ Assessment of Airway, Breathing, Circulation, and Disability (ABCD). Exposure and environmental control; Full vital signs, Five interventions (cardiac monitor, pulse oximeter, urinary catheter, gastric tube, laboratory studies), and Facilitate family presence; Give comfort measures; Head-to-toe assessment; and Inspect posterior surfaces (EFGHI).
} 
(ABCD-EFGHI; Emergency Nurses Association, 2007). Inference (3) and elaboration (4) occurs when asking learners about what could have caused the deterioration and how their hypothesis explains their observations. Finally, experimentation (5) involves reviewing interventions in light of their expected effects on the causes of the deterioration. In the end, learners describe what they learned and how they can reinvest this in their future performance. Throughout REsPoND's process and in accordance with Tanner's (2006) model, attention is given to learners' knowledge and expectations of the situation. Learners are prompted to recall and interpret the changes they noticed in the patient's situation and review their responses.

\section{METHODS}

This mixed-methods study employed a sequential explanatory design (Creswell \& Plano Clark, 2011), which aligns with the Medical Research Council's guidance (2008) that evaluating a complex intervention should focus on both its effectiveness and its active ingredients and how they exert their effect. After performing a trial to test the effectiveness of REsPoND on a clinical judgment score (Lavoie et al., 2016), we examined REsPoND's active ingredients. We adopted two research questions: (1) How do nursing students perceive that the reflection in REsPoND fostered learning and (2) How did REsPoND contribute to their clinical judgment in patient deterioration simulations? The institutional review board of our university approved this study.

\section{$\underline{\text { Sample }}$}

The sampling strategy was based on the results of the trial, where nursing students from an undergraduate critical care course experienced three scenarios of patient deterioration with a highfidelity manikin in a lab setting (see Figure 1). The scenarios concerned hypovolemic shock (HEMO), sepsis (SEPSIS), and trauma (TRAUMA). The second scenario, sepsis, was repeated twice (SEPSIS-I and SEPSIS-II). Participants in the trial $(n=119)$ experienced either REsPoND ( $n=63)$ or Plus-Delta ( $n=56$; Fanning \& Gaba, 2007) after engaging in HEMO and SEPSIS-I. An individual score of clinical judgment was obtained in all simulations. Information about the trial was provided to all students in the critical care course at the first class session. Participants were enrolled upon providing informed consent. Participation in the trial was voluntary and was not rewarded with extra credits/marks in the course. Also student data were anonymized. 


\section{Figure 1. Design of the trial}

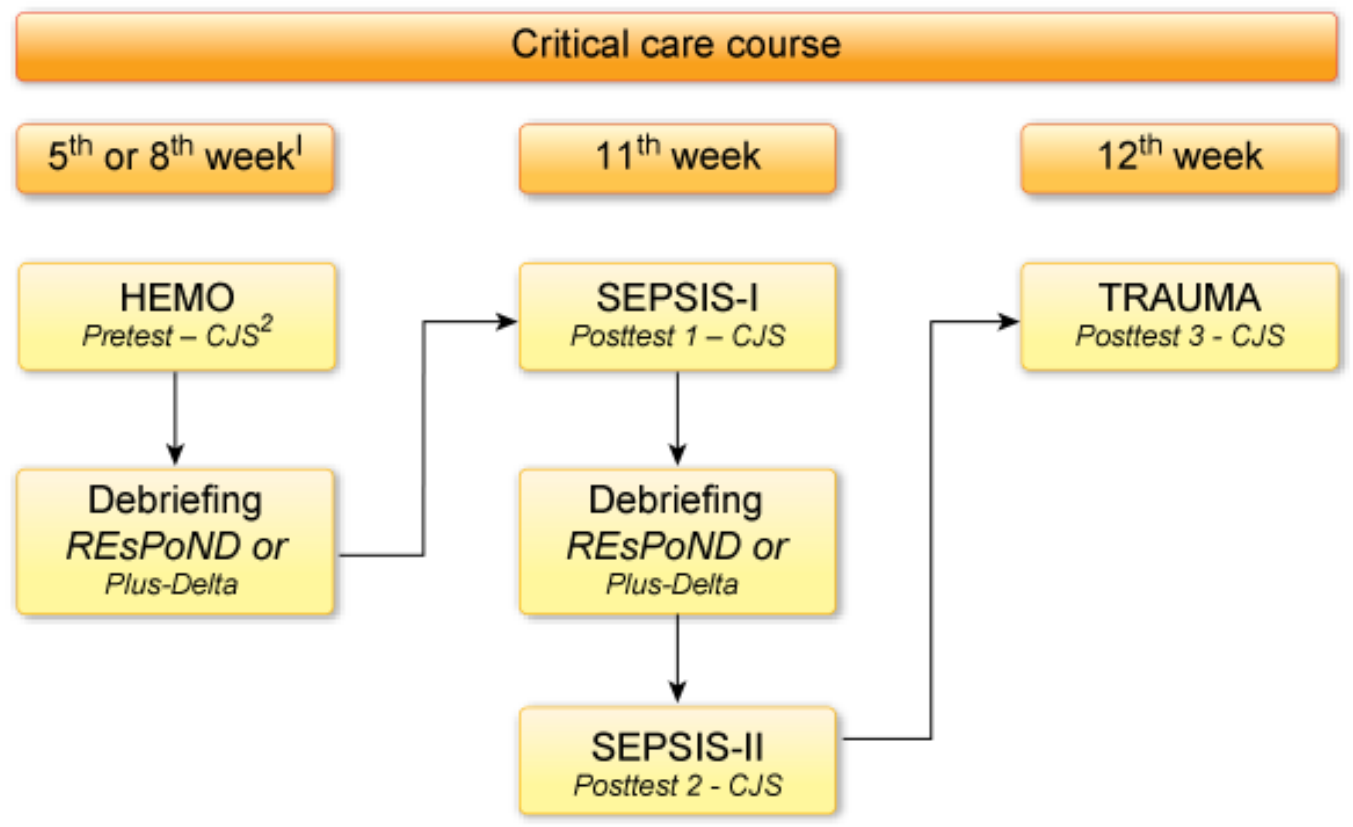

Note. ${ }^{1}$ The trial was conducted on two campuses of the university offering the same critical care course with identical content. The timing of the first simulation was planned at different times in each location. ${ }^{2}$ Clinical judgment score.

Only participants in the trial who had been assigned to REsPoND $(n=63)$ were eligible for the present phase of the study. We used a purposive sampling strategy based on the progression in their clinical judgment scores. The clinical judgment score comprised a measure of situation awareness (Lavoie et al., 2016) that operationalized two concepts of Tanner's (2006) model: noticing (situation awareness perception, 15 points maximum) and interpretation (situation awareness comprehension, 9 points maximum).

Two thirds of REsPoND students showed a variation of \pm 2 points for their perception and comprehension scores from HEMO to TRAUMA. We considered only the 34 students who showed a variation $\geq 3$ points on any of the scores as eligible for participation in this phase of the research. These students were classified into four different learning profiles: decrease in perception (Profile A, $n=6$ ), increase in perception (Profile $\mathrm{B}, n=8$ ), decrease in comprehension (profile $\mathrm{C}, n=6$ ), and increase in comprehension (Profile $\mathrm{D}, n=7$ ). Seven students belonged to two learning profiles simultaneously (Profile A and C, $n=2$; Profile A and D, $n=1$; Profile B and D, $n=4$ ). 
We sent personalized electronic invitations to all 34 eligible students; nineteen confirmed their interest to participate in a face-to-face semi-structured interview: Profile $\mathrm{A}(n=3)$, Profile $\mathrm{B}(n=$ $6)$, Profile C $(n=5)$, Profile D $(n=2)$, Profiles A and C $(n=2)$, and Profiles B and D $(n=1)$. Evolution of students' scores is presented in Figures 2 and 3.

Figure 2. Perception scores - Profiles A and B

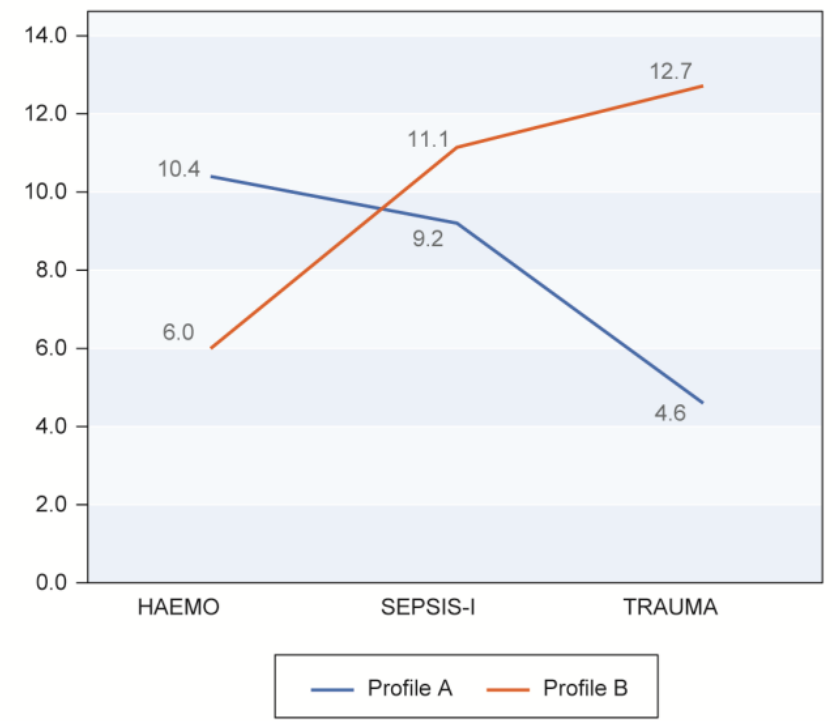

Figure 3. Comprehension scores - Profiles C and D

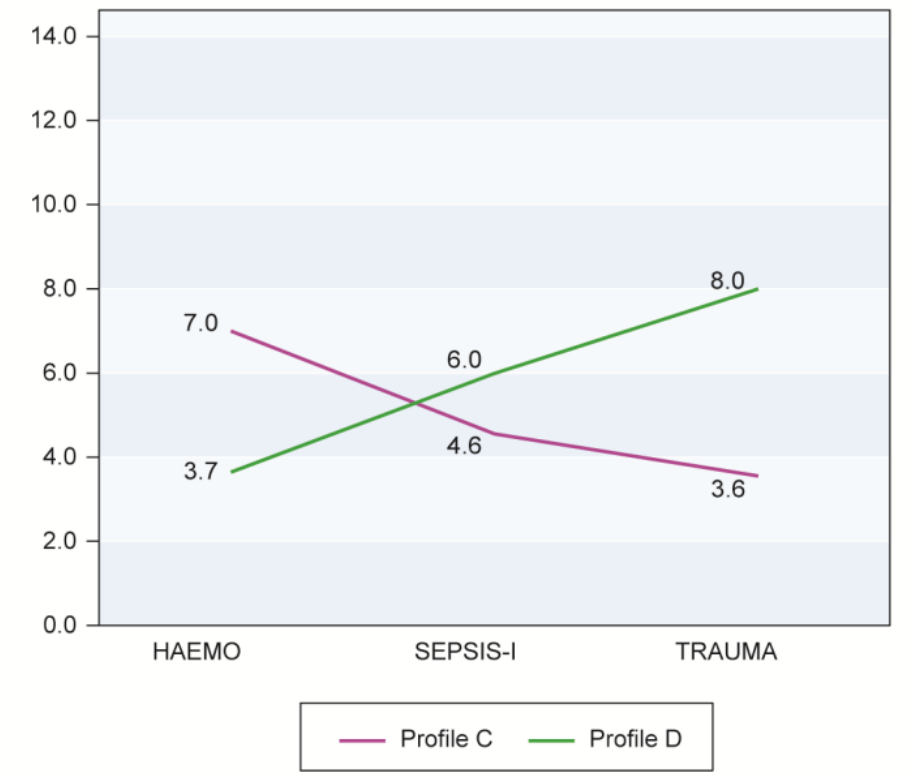




\section{$\underline{\text { Data Collection }}$}

Participants met with one of two research assistants to take part in individual semi-structured interviews. Research assistants were graduate nursing students who did not partake in the trial, were not aware of the content of REsPoND, and did not know to which profile participants belonged. Based on the research questions, the interview guide comprised five questions on REsPoND: (1) “Tell me about your experience;” (2) "What did you learn;” (3) "What was helpful to learn and why;" (4) "What was less helpful to learn and why;" and (5) other comments. Interviews were audio-recorded and transcribed by administrative agents. Interviews began two weeks after the trial and went on for two weeks in May 2015. Each lasted for 20 to $30 \mathrm{~min}$.

\section{$\underline{\text { Data Analysis }}$}

To answer the first research question, we conducted a thematic analysis (Paille \& Mucchielli, 2012) of all the transcripts without considering to which learning profile they belonged. PL listened to the audio recordings to become familiar with the data and to make sure that the transcripts were accurate. He coded the meaningful units within the transcripts. Codes were subsequently classified under general categories (e.g., experience of the simulations, learning outcomes, debriefer's interventions); in each category, related codes were combined to create a first series of themes. The relationships among the themes were scrutinized to understand how they could answer the first research question. A hierarchy of themes was created and the themes were refined until we had highlighted those that contributed to answering the research question.

To answer the second research question, we compared the findings from the thematic analysis according to participants' learning profiles. For each learning profile, we retrieved the codes that defined the themes. We grouped and reduced the codes to outline that profile's characteristics and grant depth to each theme. We compared how these characteristics differed between the profiles. When a characteristic was found to be unique to a given profile, it was defined as an "attribute" of the profile. Iterative between-profile movements allowed for refinement of each profile's attributes.

\section{$\underline{\text { Rigor and Role of the Researchers }}$}

The analytic process lasted for six months, where PL had prolonged and close contact with the data. Regular verifications from JP and SC were performed at each stage of the analysis to ensure the trustworthiness of the findings. An exhaustive audit trail was kept. The codes and themes were 
presented in an external audit to the research assistants who interviewed the students to confirm the accuracy of the interpretation. They generally felt that the description resonated with students' accounts of the debriefing. We also used interviews with students who belonged to two different profiles to confirm the referential adequacy of the attributes (Lincoln \& Guba, 1985).

All investigators contributed to the development of REsPoND and XX was involved in the delivery of the debriefings. To make sure that his position did not alter the findings in any way, data supporting the findings were presented to YY and ZZ, particularly for the categories directly related to the delivery of the debriefing (e.g., debriefer, interaction with students). Throughout the analysis, YY and ZZ challenged XX's assumptions about students' learning process.

\section{$\underline{\text { FINDINGS }}$}

Table 1 presents the sociodemographic data of the participants. We also provide a comparison with the eligible students and the students from the trial to show that they were similar.

How the Reflection in REsPoND Fostered Learning

Regardless of learning profiles, two themes were found to describe how students perceived that REsPoND fostered learning: (1) students' configuration of a framework and appraisal of their own performance and (2) guided exchanges between students as sources of insight. Quotes that support the findings are presented in Table 2.

Students' Configuration of a Framework and Appraisal of their own Performance. In REsPoND, students appeared to build a framework of the patient's situation and appraised their own performance in light of it. The framework was based on logical connections between three components: the pathophysiology (causes), the signs and symptoms (observations), and the appropriate interventions. The process to configure their framework was threefold: (1) preparing before the simulation, (2) reviewing observations in the situation, and (3) making logical connections. Students' appraisal of their performance followed two processes: (4) comparison with the framework and (5) planning for the next simulation.

In the weeks before the simulation, students prepared by reading the case story of the simulated patient and reviewing content from the critical care course. On the day of the simulation, they met with their teammates to point out potential problems and plan their actions. At this point, students 
had created a rough draft of their framework and most focused on the interventions to address problems resulting from the pathophysiology.

In the debriefing after the simulation, students further elaborated their framework by reviewing what they had observed in the simulation (Figure 4a). They recounted describing their observations through the primary and secondary assessment survey with guidance from the debriefer's questions. With this information, students described expanding their framework by making logical connections between the patient's pathophysiology and their observations (Figure 4b). Students suggested that the debriefing pushed their analysis by making them formulate and test hypotheses on how the pathophysiology could explain their observations (see Quotes 1 and 2). When they had formed plausible hypotheses to explain their observations, students recalled integrating interventions into their framework by associating interventions with pathophysiological causes and defining what changes these interventions would produce in their observations (Figure 4c). For instance, they examined how oxygen administration was relevant for a patient with respiratory distress and what effects it would have on the patient's vital signs.

\section{Figure 4. Students' configuration of a framework of the patient's situation}

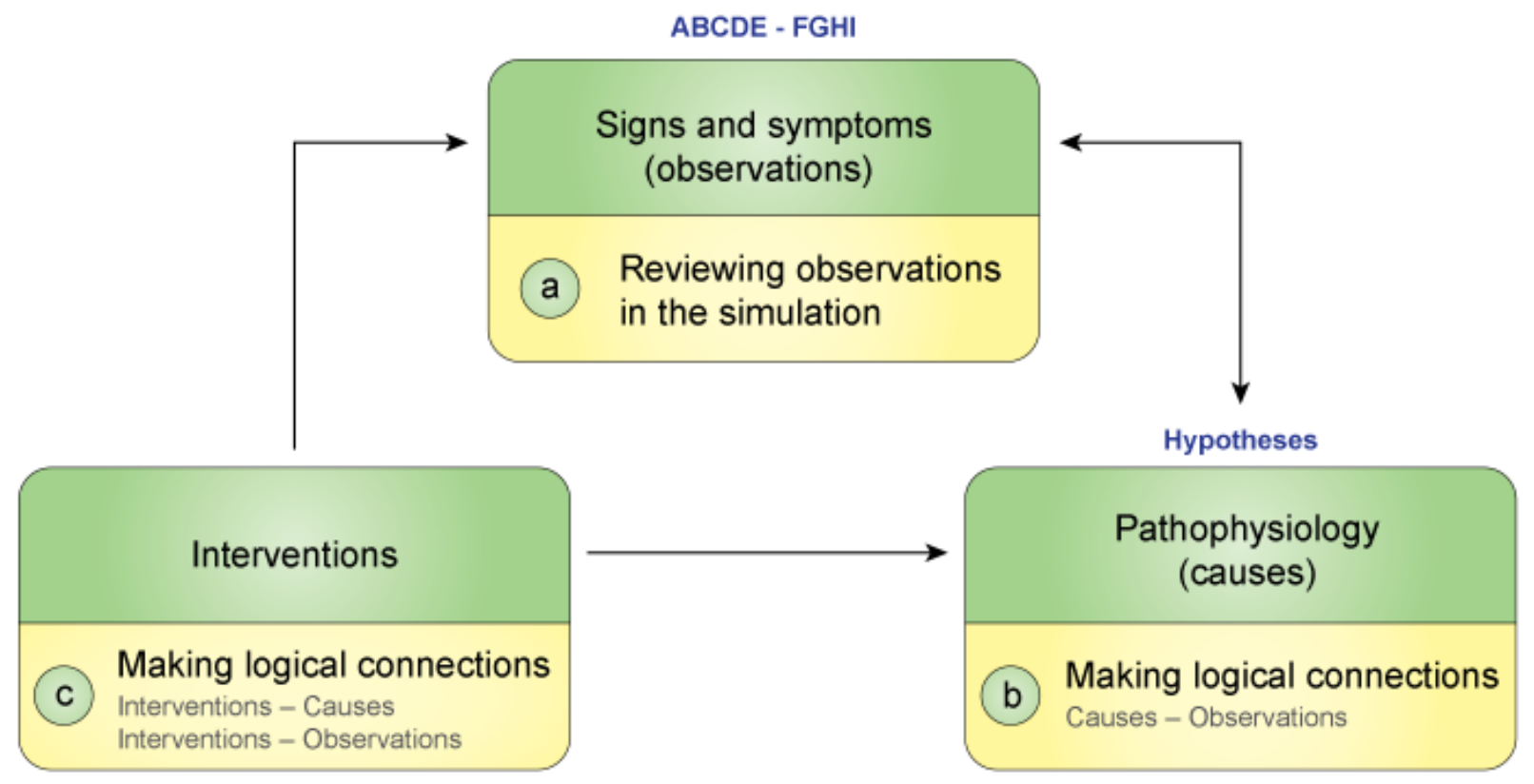

Students then appeared to appraise their performance by comparing what they did in the simulation to what they should have done according to their frameworks. This process was referred to as "pointing out their strengths and weaknesses." Students described strengths and weaknesses 
related to the completeness of their assessment of the patient, communication with teammates and the physician, and the choice or execution of interventions. Notably, students' listing of their strengths and weaknesses was not a component of REsPoND; this was solely included in the PlusDelta debriefings, which served as the control intervention in the trial.

Students recalled planning for the next simulation by turning their weaknesses into points for improvement and their strengths into points to maintain. They described how they divided tasks among group members and set objectives for the next simulations. Students appreciated experiencing the SEPSIS scenario twice because they were able to appraise their second performance and see their improvement (see Quote 3).

Guided Exchanges between Students as Sources of Insight. Students felt that their group dynamic was positive because everyone collaborated and participated to the debriefing discussion using their knowledge or viewpoints. Students felt that they had mutually added to each other's insights as a result of the diversity of their practical and theoretical knowledge. These exchanges caused them to consider aspects of the simulation that they would have neglected otherwise (see Quote 4). The small size of the groups (a maximum of six students), good communication skills and attitudes of openness and respect towards each other facilitated their teamwork.

Students described the debriefer's role as providing guidance through questions, without which students felt they would not know what to discuss. Students perceived that the debriefer motivated their reflection by demanding that they go beyond description towards analysis of what happened (see Quote 5). Students felt that the debriefer helped them orient towards what needed to be addressed and redirected them when they took the wrong path. Furthermore, the debriefer's practical experience and critical care knowledge gave him or her credibility. Students appreciated that what they did well was emphasized and that they had the right to make mistakes, since they were still learning.

\section{How REsPoND Contributed to Nursing Students' Clinical Judgment}

When considering the different learning profiles, we found that three attributes could explain how REsPoND contributed to nursing students' clinical judgment: (1) systematic and chronologic review process, (2) anticipation and early configuration of the framework, and (3) communication mostly among students. 
Systematic and Chronologic Review Process. Students whose perception score improved (Profile B) insisted on the review process. For them, the debriefing consisted mainly of going through the primary and secondary assessment survey in a systematic and chronological way. With this survey, they felt that they were able to understand what was going on with the patient and what they had to do in this situation. As such, they described their principal learning outcomes as the execution, content, and relevance of the ABCD-EFGHI (see Quotes 6 and 7). Although students from other profiles did address the review of the simulation through the ABCD-EFGHI, they mentioned it less frequently and with less emphasis.

Anticipation and Early Configuration of the Framework. Students who showed improved comprehension scores (Profile D) emphasized how they anticipated what could happen to the patient. They insisted on preparing for the simulations, which helped them reach a more thorough understanding of the situation. Before arriving in the debriefings, they already had articulated a sophisticated framework with equal emphasis on all three components - causes, observations, and interventions - to anticipate what could happen. The anticipation was also notable in how they approached the debriefings and how they recalled that the debriefer helped them project what could happen if the scenario evolved further (see Quote 8).

In contrast, students whose comprehension score remained stable or decreased (Profiles A, B, and C) put more emphasis on their performance. Their frameworks accentuated the interventions or actions in the simulations. It appeared that prior to the simulation, they worked more on planning their actions than on comprehending or anticipating the situation. In their accounts, the process of performance appraisal was particularly important, even more so than the process of review and analysis - in other words, students were more self-focused than patient-focused:

Discussion Mostly Among Students. All students described the debriefing as a discussion among themselves, under the guidance of the debriefer. However, students whose perception or comprehension scores improved (Profiles B and D) stated that the debriefer should allow students to work on their own by giving them time to reflect and answer questions. They said that the debriefer should refrain from participating in the discussions, other than guiding it (see Quote 10).

In contrast, students whose perception or comprehension scores decreased (Profiles A and C) appreciated when the debriefer answered their questions (see Quote 11). They described a need to 
know if they were right. It seemed that they put trust in the debriefer's knowledge and experience and that they valued being validated (see Quote 12).

\section{DISCUSSION}

The results of this study showed that in the REsPoND debriefings, students built a framework to understand each simulated patient's situation and appraise their performance through guided exchanges with their peers. REsPoND contributed differently to their clinical judgment depending on the following: (1) the value they placed on the systematic and chronologic review of the simulation through the primary and secondary assessment survey; (2) their focus, either on understanding and anticipating what could happen or on performing in the simulation; and (3) their preference for who participated in the debriefing discussion.

Students whose perception scores improved perceived that reviewing the simulation through the primary and secondary assessment survey was the most beneficial component of REsPoND. Thus, it appears that including the ABCD-EFGHI in the debriefing helped students develop a thorough description of the simulated experience. This relates to existing evidence that beginning nurses tend to use analytical reasoning patterns by breaking down a clinical situation into its component elements (Boyer et al., 2015; Hoffman et al., 2009; O'Neill et al., 2005; Tanner, 2006). In the ABCD-EFGHI, patient assessment is divided into a series of steps to detect life-threatening deficits and gain a comprehensive view of the patient's physical status (Emergency Nurses Association, 2007). This seems congruent with nursing students' reasoning patterns and seemed to result in a measurable improvement of some students' observation skills. Similarly, other studies have reported positive learning outcomes among nursing students exposed to the primary and secondary assessment survey in simulation (Liaw et al., 2011b; Stayt et al., 2015).

Students' comprehension scores were an outcome of interest, since clinical judgment was defined as an interpretation or conclusion regarding a patient's situation (Tanner, 2006). Students who showed an increase in this score insisted on the importance of their preparation and how they tried to anticipate what could happen in the simulations. This suggested the importance of students' expectations, which is an element of Tanner's (2006) clinical judgment model. For students in Profile D, the debriefing was an occasion to confirm their expectations and further define what to expect in subsequent simulations. Although starting to receive attention in nursing education research (Bussard, 2015; Phillips, 2014), this concept must nevertheless be further explored 
Another main finding was that most of the students built a causes-observations-interventions framework, which embodied their understanding of the situation. This reflects how Dewey (1910/2007) defined the concept of meanings as relationships between causes, actions, and consequences. However, the attributes of the learning profiles showed how most students (Profiles A, B, and C) focused on their performance and not on the patient. For those students, the framework served to appraise their performance, even though REsPoND was developed as a reflective debriefing in opposition of the evaluative type of debriefing (e.g., Plus-Delta), that rely on students' self-assessment of their simulation performance. Eva and Regehr (2008) distinguished between reflection and self-assessment by proposing that reflection focuses on understanding a problematic situation, whereas self-assessment is a judgment of one's own performance based on the application of certain standards (Boud, 1999). It is therefore questionable whether students perceived REsPoND as an opportunity to understand the patient's situation or as a means of defining and applying performance standards. It seems that even if REsPoND consisted of reflective questions without any evaluative purpose, it still generated an evaluative process comparable to Plus-Delta in students. This is rather surprising, especially since Plus-Delta served as a control group intervention in the trial. This also raises questions on the fidelity of the debriefings and how students received the intervention in contrast with the debriefers' intentions. Students' focus on performance assessment is potentially attributable to their prior experiences of simulation and debriefing or clinical placement, which often give much attention to assessment.

Students whose scores improved valued discussion among themselves, while students whose scores decreased preferred guidance from the debriefer. These findings can be linked to the concept of facilitation (Fanning \& Gaba, 2007), or the "processes by which one member of a group operates to help the group analyze issues, learn from experience, and work as a team to draw conclusions" (Dismukes et al., 2000, p. 1). Standards of best practice posit that the degree of facilitation should be adjusted to engage every participant in the debriefing process (Decker et al., 2013). However, our results suggest that students who preferred the debriefer to be less involved tended to exhibit improvements in their scores. Despite this, they still expressed a need for guidance in their reflection. Studies by Boet et al. $(2011,2013)$ showed that instructor-led debriefings and selfdebriefing with rating scales had similar effects on learners' performance of crisis resourcemanagement skills. Future research should explore how different level of facilitation and guidance with other means than a debriefer. 


\section{$\underline{\text { Limitations }}$}

One limitation of this study was the rather variable number of students interviewed in each profile. Furthermore, because of the mixed-methods design, the sample was defined after the results of the trial. While we did not aim to attain theoretical saturation, the use of this design limited the number of students eligible for the interviews. We also needed to wait until the end of the outcome measurement in the trial to start recruitment for the interviews, which may have contributed to a memory bias. The quantitative results presented above should not be considered as indicators of the effectiveness of REsPoND. Therefore, our findings should be interpreted and used with caution.

\section{CONCLUSION}

We conducted a mixed-methods study to examine the contribution of REsPoND to nursing students' clinical judgment in patient deterioration simulations. Our findings suggest that reviewing students' observations through a systematic approach to assessment was an active element of REsPoND. They also highlight the importance of considering students' expectations of a clinical situation in teaching strategies aimed at clinical judgment development. Future research is needed on the relations between reflection and self-assessment in debriefing, and to devise alternatives to educator's guidance.

\section{REFERENCES}

Boet, S., Bould, M. D., Bruppacher, H. R., Desjardins, F., Chandra, D. B., \& Naik, V. N. (2011). Looking in the mirror: Self-debriefing versus instructor debriefing for simulated crises. Critical Care Medicine, 39, 1377-1381. doi:10.1097/CCM.0b013e31820eb8be

Boet, S., Dylan Bould, M., Sharma, B., Revees, S., Naik, V. N., Triby, E., \& Grantcharov, T. (2013). Within-team debriefing versus instructor-led debriefing for simulation-based education: A randomized controlled trial. Annals of Surgery, 258, 53-58. doi: 10.1097/SLA.0b013e31829659e4

Boud, D. (1999). Avoiding the traps: seeking good practice in the use of self assessment and reflection in professional courses. Social Work Education, 18, 121-132. doi:10.1080/02615479911220131

Boyer, L., Tardif, J., \& Lefebvre, H. (2015). From a medical problem to a health experience: How nursing students think in clinical situations. Journal of Nursing Education, 54, 625-632. doi: $10.3928 / 01484834-20151016-03$

Bussard, M. E. (2015). Clinical judgment in reflective journals of prelicensure nursing students. Journal of Nursing Education, 54, 36-40. doi:10.3928/01484834-20141224-05

Cant, R. P., \& Cooper, S. J. (2011). The benefits of debriefing as formative feedback in nurse education. Australasian Journal of Advanced Nursing, 29, 37-47. 
Cheng, A., Eppich, W., Grant, V., Sherbino, J., Zendejas, B., \& Cook, D. A. (2014). Debriefing for technology-enhanced simulation: a systematic review and meta-analysis. Medical Education, 48, 657-666. doi:10.1111/medu.12432

Creswell, J. W., \& Plano Clark, V. L. (2011). Designing and conducting mixed methods research $\left(2^{\text {nd }}\right.$ ed. $)$. Thousand Oaks, CA: Sage.

Decker, S., Fey, M., Sideras, S., Caballero, S., Rockstraw, L., Boese, T., ... Borum, J. C. (2013). Standards of best practice: Simulation standard VI: The debriefing process. Clinical Simulation in Nursing, 9(s6), S26-29. doi:10.1016/j.ecns.2013.04.008

Dewey, J. (2007). How we think. Stilwel, KS: Digireads.com. (Original work published 1910)

Dismukes, R. K., McDonnell L. K., Jobe, K. K., \& Smith G. M. (2000) What is facilitation and why use it? In R. K. Dismukes \& G. M. Smith (Eds.), Facilitation in aviation training and operations (pp. 1-12). Aldershot, UK: Ashgate

Dreifuerst, K. T. (2012). Using debriefing for meaningful learning to foster development of clinical reasoning in simulation. Journal of Nursing Education, 51(6), 326-333. doi:10.3928/01484834-20120409-02

Emergency Nurses Association. (2007). Trauma nursing core course (TNCC) provider manual (6 $6^{\text {th }}$ ed.). Des Plaines, IL: Emergency Nurses Association.

Eva, K. W., \& Regehr, G. (2008). "I'll never play professional football" and other fallacies of selfassessment. Journal of Continuing Education in the Health Professions, 28, 14-19. doi: $10.1002 / \mathrm{chp} .150$

Fanning, R. M., \& Gaba, D. M. (2007). The role of debriefing in simulation-based learning. Simulation in Healthcare, 2, 115-125. doi: 10.1097/SIH.0b013e3180315539

Fisher, D., \& King, L. (2013). An integrative literature review on preparing nursing students through simulation to recognize and respond to the deteriorating patient. Journal of Advanced Nursing, 69, 2375-2388. doi:10.1111/jan.12174

Forneris, S. G., Neal, D. O., Tiffany, J., Kuehn, M. B., Meyer, H. M., Blazovich, L. M., ... Smerillo, M. (2015). Enhancing clinical reasoning through simulation debriefing: A multisite study. Nursing Education Perspectives, 36, 304-310.

Hoffman, K. A., Aitken, L. M., \& Duffield, C. (2009). A comparison of novice and expert nurses' cue collection during clinical decision-making: verbal protocol analysis. International Journal of Nursing Studies, 46, 1335-1344. doi:10.1016/j.ijnurstu.2009.04.001

Lavoie, P., Pepin, J. et Cossette, S. (2015). Development of a post-simulation debriefing intervention to prepare nurses and nursing students to care for deteriorating patients. Nurse Education in Practice, 15, 181-191. doi:10.1016/j.nepr.2015.01.006

Lavoie, P., Cossette, S. et Pepin, J. (2016). Testing nursing students' clinical judgment in patient deterioration simulations: Development of a situation awareness instrument. Nurse Education Today, 38, 61-67. doi:10.1016/j.nedt.2015.12.015

Lederman, L. C. (1992). Debriefing: Toward a systematic assessment of theory and practice. Simulation \& Gaming, 23, 145-160. doi:10.1177/1046878192232003

Liaw, S. Y., Rethans, J. J., Scherpbier, A., \& Piyanee, K. Y. (2011b). Rescuing A Patient In Deteriorating Situations (RAPIDS): A simulation-based educational program on 
recognizing, responding and reporting of physiological signs of deterioration. Resuscitation, 82, 1224-1230. doi:10.1016/j.resuscitation.2011.04.014

Liaw, S. Y., Scherpbier, A., Klainin-Yobas, P., \& Rethans, J. J. (2011a). A review of educational strategies to improve nurses' roles in recognizing and responding to deteriorating patients. International Nursing Review, 58, 296-303. doi:10.1111/j.1466-7657.2011.00915.x

Lincoln, Y. S., \& Guba, E. G. (1985). Naturalistic inquiry. Newbury Park, CA: Sage.

Medical Research Council. (2008). Developing and evaluating complex interventions: New guidance. London: Medical Research Council.

O'Neill, E. S., Dluhy, N. M., \& Chin, E. (2005). Modelling novice clinical reasoning for a computerized decision support system. Journal of Advanced Nursing, 49, 68-77. doi:10.1111/j.1365-2648.2004.03265.x

Paillé, P., \& Mucchielli, A. (2012). L'analyse qualitative en sciences humaines et sociales ( $3^{\text {rd }}$ ed.). Paris: Armand Colin.

Phillips, L. (2014). Undergraduate nursing student situation awareness during simulation (Doctoral dissertation). Retrieved from DigitalUNC (https://digarch.unco.edu/islandora/object/cogru:10550).

Raemer, D., Anderson, M., Cheng, A., Fanning, R., Nadkarni, V., \& Savoldelli, G. (2011). Research regarding debriefing as part of the learning process. Simulation in Healthcare, 6, S52-57. doi: 10.1097/SIH.0b013e31822724d0

Stayt, L. C., Merriman, C., Ricketts, B., Morton, S., \& Simpson, T. (2015). Recognizing and managing a deteriorating patient: A randomized controlled trial investigating the effectiveness of clinical simulation in improving clinical performance in undergraduate nursing students. Journal of Advanced Nursing, 71, 2563-2574. doi:10.1111/jan.12722

Tanner, C. A. (2006). Thinking like a nurse: A research-based model of clinical judgment in nursing. Journal of Nursing Education, 45, 204-211. 
Table 1. Sociodemographic data of students

\begin{tabular}{lccc}
\hline & $\begin{array}{c}\text { Students } \\
\text { interviewed } \\
(n=19)\end{array}$ & $\begin{array}{c}\text { Eligible } \\
\text { students } \\
(n=34)\end{array}$ & $\begin{array}{c}\text { REsPoND } \\
\text { students } \\
(n=63)\end{array}$ \\
\hline $\begin{array}{l}\text { Age (years) } \\
\text { Gender (female) }\end{array}$ & $21.3(1.3)$ & $22.4(4.0)$ & $23.6(5.2)$ \\
Program & $19(100.0 \%)$ & $34(100.0 \%)$ & $59(93.7 \%)$ \\
$\quad$ Entry-to-practice & $12(63.2 \%)$ & $22(64.7 \%)$ & $43(68.2 \%)$ \\
$\quad$ Post-diploma & $7(36.8 \%)$ & $12(35.3 \%)$ & $20(31.8 \%)$ \\
Continent of origin & & & \\
Africa & - & - & $3(4.8 \%)$ \\
Asia & $2(10.5 \%)$ & $3(8.8 \%)$ & $6(9.5 \%)$ \\
Europe & - & $2(5.9 \%)$ & $4(6.3 \%)$ \\
North America & $16(84.2 \%)$ & $27(79.4 \%)$ & $47(74.6 \%)$ \\
South America & $1(5.3 \%)$ & $2(5.9 \%)$ & $3(4.8 \%)$ \\
\hline
\end{tabular}

NOTE: Data are means (standard deviations) or frequencies (\%) 
Table 2. Supporting quotes

\section{Quote}

$1 \quad$ It pushed us to delve further: we asked questions to others and we tried to answer and to emit hypotheses. Could it be that? Yes. Why? (Participant B-28)

2 Together with my knowledge and those of others, we made hypotheses or deductions. He had this symptom because of that... He showed this arrhythmia because of that other reason. (Participant B-125)

3 In the afternoon, we did it again and it was perfect. What we did in the morning, we did in half the time because we were clearer, we knew where we were going, and we had revised. [...] In the morning, we acted haphazardly. [...] In the afternoon, we knew what to do. [...] So, I think that doing [the simulation] again makes us realize how important it is to debrief. (Participant A-105)

4 [What was helpful to learn] was really the collaboration between students. Sharing our views, our knowledge. Challenging each other. We did not see the situation in the same way. When someone else shares their views, you get a more global perspective on the situation than only your way of seeing things. (Participant B-125)

5 The debriefers asked many questions so that we would understand what we were doing, instead of just doing it. We tried to understand the pathophysiology, what was behind our assessment. They made us think things through and not only name stuff. (Participant C-46)

6 We went through the ABCD-EFGHI, which I found really relevant. [...] If you do that, you will end up seeing the patient in his entirety. It is organized so that you see everything and don't miss a thing. (Participant B-94)

7 What I remember the most was that we did the ABCD in depth. We checked every point that we should assess for every patient, then those that were important for this particular patient, $[\ldots]$ [and then] those that changed in this patient's condition, [or] what we were facing. (Participant B-43)

8 [The debriefing] confirmed the hypotheses that I already had, since we could prepare. I looked in my books, already made plenty of linkages, and wrote what I wanted to do. [...] [In the debriefing], they really put us in the context with 'What ifs': 'What if this happens? If that happens, what will you do?' It seems that it prepared us to suppose what could happen and do our own hypotheses. In the end, they asked questions, but we were the ones who supposed and made the hypotheses. (Participant D-34)

9 It helped to ponder how we acted, if it was correct, what we could have done in other situations. If you never reflect on that, you can never improve or change the way you act. [...] You don't always need to learn about the pathophysiology. It's good to learn what you are and what you are capable of. (Participant C-46)

10 It was better when the debriefer stood back, guiding us, but we were the ones discussing. I liked it less when [the debriefer] was a part of our team. I think the debriefer has more of a supporting role, not a teammate role. [...] I learned more when we were on our own. Guided with questions, but [still] on our own. (Participant B-125) 
11 We always want answers. We don't want a question as an answer. (Participant A-09)

12 Whatever we do, we never got confirmation that it was correct. I think it would be helpful if the debriefer said: 'That was not necessary' or 'That was good'. A little more feedback would be good. I know the goal is that we find it on our own, but at some point, we've been through it all and we wonder if we are right. That would help to set our objectives, since someone with the knowledge pointed it to you. (Participant C-44)

NOTE. All quotations are translated from French. 